\title{
CHRISTELIKE ONDERWYS IN DIE PRAKTYK: 'N EVALUERING VAN DIE HUIDIGE STAND VAN SAKE
}

\author{
J.L. van der Walt \\ Departement Fundamentele en Historiese Opvoedkunde \\ PU vir $\mathrm{CHO}$ \\ POTCHEFSTROOM
}

\begin{abstract}
Despite manty years of reflection on and discussion of the theory and practice of Christian education in the RSA and other parts of the Western world, full justice has so far not been done to the ideals of Christian education in the practical situation of the classroom. This conclusion is drawn on the basis of an analysis of certain utterances by educationalists from four different parts of the world as well as on an analysis of some books gencrally used in RSA schools. The article is concluded with some suggestions lowards recifying the matter.
\end{abstract}

\section{INLEIDENDE OPMERKINGS}

Daar word in verskillende lande steeds baie ernstig besin oor die presiese aard van Christelike onderwys. In Nederland is die besinning in der waarheid al eeue lank aan die gang - vandag miskien meer intensief as ooit tevore vanweë die gesekulariseerdheid van die samelewing aldaar. Hierdie besinning is ook in Noord-Amerika, Australië en hier te lande sterk op dreef. 'n Byeenkoms wat die VCHO-tak van Pretoria laat in 1989 oor hierdie aangeleentheid gereël het, dui daarop dat die gesprek vandag nog uiters aktueel is.

In hierdie artikel word word die vraag of Christelike onderwys inderdaad in die praktyk tot sy reg kom van veral twee kante of gesigspunte benader:

a. Eerstens word daar gelet op enkele resente uitsprake van denkers oor die moontlikheid van Christelike onderwys in die vier vermelde lande, veral met die oog daarop om vas te stel of hulle meen die aangeleentheid kom in die praktyk behoorlik en voldoende tot sy reg.

b. Ten tweede word die situasie hier te lande in meer besonderhede bekyk deur verskillende handboeke wat in skole gebruik word, te ontleed. Om te toon wat wel gedoen kan word om die saak van Christelike onderwys in die skole tot uitdrukking te bring, word ten slotte gelet op leerinhoude wat in die vorm van werklike lesse vir die skool uitgewerk is en wat as 'n moontlike model vir 
Christelike of Skrifmatige onderwys in die praktyk kan dien.

\section{VIER RESENTE UITSPRAKE OOR CHRISTELIKE ONDERYS EN DIE MOONTLIKE TOEPASSING DAARVAN IN DIE PRAKTYK ${ }^{1}$}

\section{1 'n Nederlandse beskouing van die saak}

Taamlik onlangs het daar 'n werk in Christelike kringe verskyn (Bregman \& Kole, 1987) waaruit blyk dat besinning oor hierdie en aanverwante vraagstukke vandag uiters aktueel is. Veral die hoofstuk uit die pen van Budding (p. 268 e.v.) is vir die vraagstuk wat in hierdie artikel aangespreek word, relevant. Die skrywer wys daarop dat die besinning oor die wese van die reformatoriese onderwys nog steeds van groot betekenis is vir Christene in Nederland. Hy is egter daarby van mening dat daar nie meer van die reformatoriese onderwys sprake kan wees nie, aangesien dit te pretensieus sou wees om so daarna te verwys, afgesien nog daarvan om dit in die praktyk tot sy reg te laat kom. Ietwat sinies sê hy: "Het is hier een jagen naar en het blijft alles ten dele."

Budding vind dit nie in orde dat daar in Nederland ook reformatoriese skole is nie; alle skole behoort na sy mening reformatories te wees. Skole wat God nie eer en dien nie, meen hy, behoort gesluit te word en die subsidies van die regering behoort beëindig te word. Hy vervolg: "De plaats van reformatorisch onderwijs moet alles beheersend, totaal omvattend zijn. Hoe ontzettend ver daar vandaan is de praktijk." (p. 269.)

As hy opnuut die wese van die reformatoriese onderwys onder die aandag van die Christelike kerke in Nederland bring, omskryf hy dit soos volg: "Dat is onderwijs, dat gericht is op het doel. Het grote doel. Dat God Drieënig word verheerlijkt in al Zijn

\footnotetext{
' Hiermee word die terrein waarop beweeg word, doelbewus afgebaken. Die doel met die oorsig van die uitsprake van hierdie vier denkers is om aan te toon dat die situasie wêreldwyd aandag geniet (en selfs kommer wek), en nie om daarmec te suggereer dat die vitsprake of bydraes van ander denkers onbelangrik is en tersyde gelaat behoort te word nie. Enigiemand wat enigsins op hoogte is met die problematiek wat in hierdie artikel behandel word, sal bewus wees van die belangrike bydraes op hicrdie gebied van die "Torontoskool" (mense soos John Vriend, James en Jean Olthuis, John van der Stelt, John van Dyke, Harro van Brummelen, Geraldine Steensma, om slegs enkeles te noem), van Pretoriase opvoedkundiges soos Willem Landman en Stanley Roos, Bloemfonteinse denkers (opvoedkundiges en filosowe) soos H.J. Strauss en D.F.M. Strauss, Pieter Schoeman en sy voorgangers, van die indertydse professor in die Vergelykende Opvoedkunde aan die Universiteit van Suid-Afrika, H.J.S. Stone, en sy opvolgers, en van die mees resente ontwikkeling in Noord-Amerika - die bydraes van die sterk opkomende New Christian Right / die Christian Day School Movement.
} 
aanbiddelijke deugden." God moet deur die onderwys die eer ontvang. "Er zijn geen facetten, geen vakken, maar ook geen mensen die aan dat doel onttrokken mogen worden." Hiermee stel die skrywer van hierdie gedeelte die eis dat die ideaal van Christelike of reformatoriese onderwys ook in die praktyk tot sy reg behoort te kom. Die reformatoriese onderwys moet gerig wees op die mens, die kind, en die jongmens, om sodoende middele in die hande van God te word en te wees, sodat die jongmense kan kom tot die vermelde doel, tot die regte verhouding met God, deur die geloof in Jesus Christus. Hy sluit hierdie besinnende paragraaf af met die versugting: "Hier is de poort eng en de weg nauw. ... Wie is tot deze dingen bekwaam? De mens Gods moet volmaakt worden toebereid, tot alle goede werken bekwaam. $O$, welk een hoge roeping, welk een heerlijke en in eigen kracht onmogelijke taak voor reformatorische onderwijs." (p. 270.)

Uit hierdie enkele baie onlangse (ietwat emosionele) besinning oor die probleem van Christelike (respektiewelik reformatoriese) onderwys in Nederland, blyk dit baie duidelik dat, ten spyte van 'n lang Christelike tradisie in daardie land, sake rondom die aanbieding van Christelike onderwys so agteruit gegaan het dat dit baie moeilik is om die praktiese toepassing daarvan te bewerkstellig. En dan word nie eers na die belemmerende rol van die huidige regering/owerheid in die saak verwys nie.

\subsection{Australië}

In Australië word die vaandel van Christelike onderwys veral gedra deur voorstanders van Christelike privaatskole. Een van hierdie vaandeldraers is Stuart Fowler. In 'n boek van hom wat onlangs uitgegee is (Fowler, 1987), sê hy soos die skrywer wat pas hierbo aangehaal is dat "any educational practice that deserves the name Christian cannot be a neatly packaged system that has all the answers worked out. In educational practice ... the Christian way is the way of constant pursuit of the goal. Its characteristic is pursuit, not arrival" (p. 195). Met hierdie uitspraak maak hy dit duidelik dat daar nooit moeg geword mag word vir die taak om die Christelike onderwys in die praktyk van die skool tot sy reg te laat kom nie, maar andersyds ook dat dit'n voortgaande taak is wat moeilik as afgehandel beskou kan word. Om hierdie rede voer hy aan: "It is not a system but a movement toward a goal in which there is a constant re-evaluation and reformation of all theory and practice in the light of God's Word." (p. 195.)

Hy onderstreep dat Christelike onderwys nie net 'n modifikasie mag wees van enige ander onderwys nie. "It must be an alternative education developed from a completely 
different root of life. It must differ, not merely in its details, but in its most fundamental principles." (p. 195.) Christelike onderwys moet gevorm en bepaal wees deur die religieuse beginsel wat in die Skrifwoord van God geopenbaar is.

Hierdie standpunt herhaal Fowler in ander woorde in 'n nog resenter werk (Fowler, 1989). Omdat hy die voorlegging namens 'n Christelike skool aan 'n sekulêre regering maak, is Fowler daarop bedag om nie te eksplisiet te wees nie; daarom stel hy die gedagte van die uniekheid van Christelike onderwys versigtig in die volgende woorde: "School education is a value-governed enterprise. The influence of values cannot be confined to a component added to a basic value-free education. The whole educational enterprise is shaped by one or another set of values." (p. 2-5.) Omdat dit die geval is, pleit hy vir die erkenning van 'n hele aantal skole wat uitdrukking sal kan gee aan die verskillende waardesisteme in die Australiese samelewing.

\section{Suid-Afrika}

In Suid-Afrika kan daar ' $n$ hele aantal voorstanders van Christelike onderwysteorie en -praktyk geidentifiseer word. Een van die mees invloedryke voorstanders van Christelike onderwysteorie en -praktyk is P.G. Schoeman. In 'n werk van hom wat enkele jare gelede die lig gesien het (Schoeman, 1983), sê hy onder andere: "In die radikale en integrale Godgerigte grondslag ... word 60k die reformatoriese pedagogiekdenke gefundeer, en hierdie sin-idee beheers ook en lê ten grondslag aan alles wat vanuit hierdie gesigshoek oor die pedagogiese in ál sy geledinge te sê is." (p. 110.) Hy dring ook daarop aan dat hierdie teoretiese waarheid in die praktyk van die opvoeding en onderwys gestalte moet kry: "Aangesien dit dan duidelik blyk dat God die absolute Soewerein oor sy skepping is, beteken dit gewis dat ook die pedagogiese, net soos alle ander menslike handelinge of bemoeienisse met die skepping, doelbewus na God 'ontsluit', dit wil sê aan Hom gewy moet word ..." (p. 111.) Hierdie beginsel geld vir al die doen en late van die opvoeder, ook vir die praktiese opvoedingsbemoeienisse met die opvoedeling. Deur sy totale betrokkenheid op sy Oorsprong word die opvoeder verhef tot vrye wese onder die absolute wet van God en in hierdie lig word vrye diens aan God, in die vorm van 'n lewensroeping of -taak tot sy eer verrig, ook in sy lewe 'n heerlike werklikheid (p. 111-2).

Ook uit hierdie bondige weergawe van die beginselstandpunt wat Schoeman stel, word dit duidelik dat die beginsel van Christelike onderwys praktyk behoort te word. 


\section{$2.4 \quad$ Noord-Amerika}

Daar bestaan in hierdie geweste vandag ' $n$ hele aantal inrigtings en persone wat erns maak met die saak van Christelike onderwys. 'n Mens sou enigeen van hulle vir die doeleindes van hierdie oorsig kon kies. Die keuse het egter op 'n heel resente artikel van John van Dyke (1988-9) geval, juis omdat hy die afwesigheid van noemenswaardige en betekenisvolle neerslag van die beginsel in die praktyk betreur. Hy sê onder andere: "I have in mind the various sorts of Christian philosophical and theological theories, such as those which talk about schooling for the glory of God, about education in the light of the Bible, of students as image-bearers of God and the like." (p. 4). Hierdie soort teoriee is gefundeer in die Bybelse beginsels, maar voeg hy by: " ... too often they leave the realm of Christian educational practice virtually untouched. Too often they are just a lot of talk!" (p. 4.) Met die beginsel van die saak het hy geen probleme nie, maar wel met die praktykwording van die beginsel: "My concern is with the fact that our theories do not translate into practice." (p. 4.) Hy verwys na veronderstelde invloedryke publikasies oor die aangeleentheid en vra dan: "But what tangible effect do these documents have on classroom practice?" (p. 4.) Na sy oordeel lewe die gemiddelde onderwyser in twee sirkels wat mekaar maar net skrams sny: die een sirkel bevat die erkende en aanvaarbare besinning oor Christelike onderwys; die ander bevat die alledaagse werklikheid in die skool waarmee die onderwyser te doen kry. Hy vervolg: "Most teachers find it difficult, if not impossible, to get these two circles to coincide, or even to intersect in some way. For many teachers these two circles hardly touch each other at all. They represent two seperate, unrelated worlds." (p.4.)

\subsection{Voorlopige konklusie}

In die voorafgaande vier paragrawe is daar slegs kortliks stilgestaan by die gedagtes van vier beginseldenkers uit vier uiteenlopende wêrelddele. Uit hierdie oorsig het dit geblyk dat daar by opvoeders nie meer enige onduidelikheid bestaan oor wat Christelike onderwys in beginsel behels nie. Ook het dit duidelik geword dat hierdie beginsel in die praktyk tot sy reg behoort te kom, maar dat dit in baie gevalle nie gebeur nie. Soos Van Dyke sê, dit bly by praat oor die beginsel. Die vraag is of dit ook hier te lande die geval is. Om dit vas te stel, is daar drie handboeke wat leerlinge in skole in Suid-Afrika gebruik, ontleed: een uit die standerd 3-jaar, een uit die standerd 6-jaar en een uit die standerd 8-jaar. Die boeke is op ewekansige wyse gekies deur gewoon vir 'n leerling uit die besondere standerd te vra om een van sy handboeke te 
leen. Die boek wat die leerling uit die boektas opgediep en oorhandig het, is vir hierdie doel ontleed.

\section{BEVINDINGE NA DIE ONTLEDING VAN DRIE SKOOLHANDBOEKE WAT IN DIE RSA GEBRUIK WORD}

Die standerd 3-boek wat vir die doel ontleed is (Visser, Nagel en Barnard, 1981), verskaf 'n kort voorwoord aan die onderwyser waarin enkele didaktiese aspekte van die aardrykskunde-onderrig gestel word. Een sin word aan die doel van die onderrig afgestaan: "Die doel van hierdie handboek en die wyse waarop die leerstof aangebied moet word, is om die leerling reeds hier in die laer klasse tot begrip te lei en tot denke te stem." (Voorwoord.) Hierdie so goed as positivistiese doel met die onderrig word met 'n deurlees van die hele boek bevestig: groot klem word op die feite van die aardrykskunde gelê, en daar is van enige "filosofiese" (Christelike-lewensbeskoulike) inslag so goed as geen sprake nie. Soms leen die situasie hom vir sodanige dieptedimensie, soos by die aanvang van hoofstuk 5 waar daar oor natuurlike plantegroei gehandel word: "Plantegroei soos bome, bosse, struike, rankplante, bossies en gras wat nie deur die mens aangeplant is nie, is natuurlike plantegroei," beweer die skrywers. "Dit is plante wat self opkom en groei sonder die sorg van die mens", word aangevoer (p. 42-3). Oor waterhulpbronne en waterbewaring sê die outeurs: "As 'n mens regtig dors is, is daar niks beter om die dors te les as 'n glasvol koue water nie. Die mens, dier en plant, het almal water nodig om aan die lewe te bly, daarom kan ons sê 'water is lewe'. Daar is haas geen plek in die samelewing waar ons sonder water kan klaarkom nie." (p. 47.) Op hierdie trant gaan dit voort: "Die watersiklus veroorsaak reën. ... Die proses (= die watersiklus) herhaal homself oor en oor." (p. 53.)

'n Aantal verdere aanhalings: "Al die mense het voedsel nodig en is van die boere afhanklik vir hul voedsel." (p. 54.) "Beesboere het met baie probleme te kampe. Beeste word gepla met bosluise wat siektes versprei en die beeste verswak. ... Droogte is nog 'n probleem waarmee die beesboer te kampe het ..." (p. 58.) "Plae: Boor- en snywurms rig baie groot skade aan mielies aan." (p. 67.) "Die RSA is een van die rykste lande ter wêreld. Hierdie rykdom kan in 'n groot mate toegeskryf word aan die baie minerale wat in die Suid-Afrikaanse bodem is. ... Suid Afrika is met baie rykdomme geseën, en die mens beskik oor die vermoë om hierdie rykdomme tot voordeel van die land en sy inwoners aan te wend." (p. 85.) (Let op die gebruik van die onpersoonlike styl in hierdie laaste sin.) "Ystererts is die delfstof wat in die moderne werreld seker die meeste in aanvraag is. ... Suid-Afrika is gelukkig om groot reserwe ystererts te hê." (p. 106.) Oor vervaardiging word bloot gesê: "Julle het al baie geleer 
van myne, fabrieke, elektriesekrag (sic), landbouprodukte en water. In 'n moderne land soos Suid-Afrika, is dit faktore wat meehelp om die mens se lewenstandaard te verhoog. Die mens wend hierdie bates aan tot voordeel van die land, deur werksgeleenthede vir mense te bied, fabrieksgoedere te maak vir binne-sowel as buitelandse markte." (p. 117.) "Die inwoners van die Republiek van Suid-Afrika bestaan uit verskillende groepe. ... Elke groep bestaan weer uit verskillende volke, geken aan sy eie taal en gewoontes. So ken ons 'n groep aan die taal wat hulle praat, asook hul gewoontes." (p.156.) "Selfs op godsdiens gebied (sic) is daar baie verskille en ooreenkomste. Meeste van die blankes is Christene, terwyl die Indiërs en Maleiers meestal Mohammodane (sic) is. Baie Swartmense en Kleurlinge is ook Christene of Mahommodane (sic). Dit is dus duidelik dat die verskillende bevolkingsgroepe in die RSA baie verskille asook ooreenkomste het. Die belangrikste ding om te onthou is dat ons almal moet leer om in vrede met mekaar te leef omdat ons almal graag welvarend wil wees. Ons is almal afhanklik van mekaar." (p.162.) As daar oor die skoonheid van die land gehandel word, word gesê: "Die natuur het aan Suid-Afrika pragtige natuurskatte gegee in die vorm van wildsoorte ..." (p. 163.)

Op hierdie wyse kan die voorbeelde vermenigvuldig word van positivistiese, neutralistiese en selfs naturalistiese uitsprake in hierdie werk. Belangriker egter as dit wat wel gesê word, is dit wat verswyg word. As 'n mens in aanmerking neem dat in die Voorwoord daarop aanspraak gemaak word dat die nuwe leerplan vir standerd 3 in hierdie boek aangebied word om aan die vereistes van die verskillende Onderwysdepartemente in Suid-Afrika te voldoen, het 'n mens inderdaad rede tot kommer oor die volslae gebrek aan gevoeligheid vir wat Christelike onderwys behels wat daaruit spreek. Uit die bondige definisies en omskrywinge in paragraaf 2 hierbo is dit al klaar duidelik dat hierdie boek nie aan die standaard vir Christelike onderwys voldoen nie: dit is duidelik dat God nie die eer in hierdie boek ontvang nie, nie in dit wat eksplisiet gestel word nie, maar bepaald ook nie in dit wat doelbewus verswyg word nie. Tewens, God word selfs oneer aangedoen as beweer word dat die natuur die RSA met natuurskoon bedeel het. Dit is duidelik dat die invoering van hierdie boek in die onderrig van die vak besondere eise op die skouers van die onderwyser sal lê: die droë positivistiese feite wat in die boek aangebied word, moet deur die onderwyser in die regte lewensbeskoulike raamwerk vertolk word sodat God inderdaad deur die leerlinge geken kan word deur middel van die onderrig, en sodat God die eer kan ontvang wat Hom toekom.

Die standerd 6-boek wat ontleed is (Lategan \& De Groot, 1983), volg 'n trant wat nie noemenswaardig van die standerd 3-boek hierbo verskil nie. Die skrywers beweer 
tereg: "Die groot bydrae van Bedryfskennis ter ontwikkeling van die hele mens en elke mens kan beswaarlik oorskat word en daarom word die hoop uitgespreek dat hierdie werk sal meehelp om die kind, as toekomstige lid van ons samelewing, volwaardig sy plek te laat inneem." (Voorwoord.) Ter beantwoording van die vraag "Hoekom moet ons teken?", gee die skrywers 'n antwoord wat net sowel in enige ander handboek ter wêreld van toepassing kan wees, naamlik dat dit ter wille van beter beplanning gedoen moet word, en omdat dit goedkoper is as om die produk te vervaardig en daarna die foute te probeer regstel (p. 1). Van die noodsaaklikheid om te leer om tegnies te teken ter uitvoering van die kultuuropdrag van God aan die mens is hier geen sprake nie. Nog 'n geleentheid om die Bybelse perspektief in die leerinhoude in te bou, gaan verlore in die volgende bespreking oor hout en houtsoorte: "Met ' $n$ inheemse houtsoort word bedoel 'n houtsoort wat in 'n land of gebied van nature daarin voorkom. Ons praat dus van inheemse houtsoorte van Suidelike Afrika en bedoel daarmee die houtsoorte wat op 'n natuurlike wyse in die Suidelike deel van Afrika voorkom. Ander houtsoorte is uitheems en hulle is deur die mens hier aangeplant." (p. 81.)

Die gedeelte oor gereedskap (p. 98 e.v.) laat eweneens die geleentheid verbygaan om te wys op die rol van die tegniek in die uitvoering van die mens se kultuuropdrag; dat God die mens in staat gestel het om gereedskap te ontwikkel om sy eie beperkinge as mens te probeer oorkom. In hoofstuk 8 (p. 170 e.v.) waar oor persoonlike veiligheid gehandel word, word nagelaat om daarop te wys dat die Skrif belangrike aanwysings gee vir die liefde vir die self en vir die belangrikheid van die lewe en liggaam. Die uiteensetting is bloot funksioneel en kon ewe goed in enige nie-Christelike handboek voorgekom het. Dieselfde geld vir die behandeling van padveiligheid en verkeersreëls (p. 172 e.v.), en vir die behandeling van die gevare van elektrisiteit (p. 179).

Die Natuur- en Skeikundeboek vir standerd 8 (Brink \& Jones, 1986) wat ontleed is, vermeld geen noemenswaardige onderrigdoelstelling in sy voorwoord nie, slegs "gebruiksaanwysings". Volgens die skrywers is dit "in die wetenskap belangrik dat konsepte en teorieë uit eksperimentele waarneming en ontdekking ontwikkel. ... In hierdie ondersoeke (waartoe die boek die leerlinge lei - VdW) word vrae gestel wat die leerling self in staat stel om die teorieë en beginsels af te lei." Die skrywers vervolg: "Sekere afdelings word in meer diepte behandel as wat deur die sillabus voorgeskryf word in 'n poging om bevredigende verklarings vir natuurverskynsels te verskaf. Die klem moet altyd op begrip van die verskynsels wees eerder as 'n blote leerproses van feite." (Voorwoord.) In hierdie laaste sin word iets van 'n anti-positivistiese houding by die skrywers verneem, maar van 'n eksplisiete Christelike benadering tot die vak word niks verneem nie. Die voorwoord kon net sowel voorgekom het in 'n boek wat deur nie-Christene geskryf is. 
In hierdie boek word met allerlei natuurverskynsels gewerk, die leerlinge word bekend gestel met die natuurwette wat die werking van die verskynsels beheers, maar enige transendente verklaring vir die werking van die wette en die prosesse is sorgvuldig vermy. Om die waarheid te sê, hierdie werk is 'n uitstekende voorbeeld van n positivistiese aanpak, en dit terwyl dit sig ten volle leen vir die aanbieding van Christelike of Skrifmatige onderwys. Dit wemel van geleenthede om God uit sy skeppingswoord of -openbaring te leer ken: eksemplare van God se handewerk soos klank, lig, magnetisme, die atoomstruktuur van materie, chemiese prosesse kom daarin aan bod.

Op grond van hierdie steekproef kan 'n mens nie anders nie as om te konkludeer dat, ten spyte van dekadelange pogings aan die kant van opleiers van onderwysers, daar so goed as niks tereg gekom het van Christelike, Skrifmatige of reformatoriese onderwys in die praktyk van die klaskamer nie. Wat tot nadenke stem, is dat van die handboeke wat hierbo ontleed is, saamgestel is om te voldoen aan die vakkurrikulum-vereistes van al die verskillende onderwysdepartemente, minstens dié vir die blanke bevolkingsgroep in die RSA. Nie eens een Bybelse perspektief op die leerinhoude kom daarin voor nie; die leerlinge leer om met die inhoude op 'n positivistiese wyse om te gaan.

Op grond van die voorgaande konklusie is 'n mens dus verplig om ook in die geval van die RSA tot die konklusie te kom dat die teorie van Christelike onderwys nie in die praktyk gestalte vind nie. Die onderwysers wat in hulle opleiding aan 'n Christelike, Skrifmatige of reformatoriese aanpak tot hulle vakke blootgestel is en daarin opgelei is, kry in die skole nie meer daarmee te doen nie. Gevolglik verdwyn die entoesiasme vir Christelike onderwys wat tydens die inisiële opleiding opgedoen is met verloop van tyd vanweë die harde realiteit van die skool- en klaskamersituasie. Hiermee word daar 'n bose kringloop geskep: die onderwyser in die klaskamer gee maar toe en gee die onderrig op 'n gewaande neutrale, selfs pragmatiese en positivistiese wyse, die leerlinge leer die inhoude op hierdie patroon, en as hulle dan op universiteit of kollege kom, moet hulle as voornemende onderwysers 'n totale heroriëntering ondergaan. Dit neem 'n hele tyd om hulle weer so te heroriënteer, en as hule gereed is vir die taak in die skool, word hulle weer tot die realiteite in die onderwyspraktyk geskok.

\section{4. 'N MOONTLIKE OPLOSSING?}

Dit is maar taamlik laat in die dag om nou nogeens met 'n oplossing te probeer kom. Bowendien is baie van die onderwysers wat vandag in die praktyk staan, in die aard en 
Christelike onderwys in die praktyk

wese van Christelike, Skrifmatige of reformatoriese onderwys opgelei, en 'n mens sou dus verwag dat hulle sou weet hoe om dit in die klassituasie toe te pas. Om nou, agterna, met wenke te kom, sou dus nie regtig 'n doel dien en van ware nut wees nie. Die strategie wat nou gevolg moet word, is dat belanghebbende groepe (soos die TO, VCHO, die TAO) die saak opneem en onder die aandag van die betrokke onderwysowerhede bring. Die vertroue word gekoester dat hierdie owerhede gevoelig sal wees vir die saak wat onder hulle aandag gebring word. Indien sodanige verantwoordelike persone egter self 'n positivistiese, pragmatiese, nominalistiese of fenomenistiese wetenskapsbeskouing huldig, sal dit uiters moeilik wees om hulle tot ander insigte te bring. Desnietemin sal die stryd vir Christelike onderwys onverpoosd moet voortduur, al is die vrugte op die arbeid nie soveel as wat verwag kan word nie.

Om gewig aan die pleidooi voor die owerhede te lewer, kan 'n mens weer eens terugval op enkele klassieke voorbeelde van lesse wat uit 'n Christelike, Bybelse of reformatoriese perspektief aangebied is (vgl. Fowler, 1987:155 e.v.; ook De Graaff \& Olthuis, 1973). Daar moet sterk daarop aangedring word dat, ten einde te kan voldoen aan die eise wat 'n Christelik-nasionale benadering tot die onderwys stel, daar 'n liggaam in die lewe geroep behoort te word wat tot Skrifmatige kurrikulering in staat sal wees. Die kundigheid bestaan reeds in die land, en daar kan ook gebruik gemaak word van die kundigheid wat oorsee beskikbaar is. Wat egter daarvoor nodig is, is 'n drastiese besluit om afstand te doen van die huidige positivistiese benadering tot die leerinhoude en daarmee saam van die handboeke wat in hierdie trant geskryf is. Die huidige vakkurrikulum moet uitgefaseer word en nuwes met 'n reformatoriese perspektief moet in hulle plek kom. Dieselfde geld vir die handboeke.

Miskien is hierdie voorstel te idealisties, gegewe die huidige onderwysbestel. 'n Stap in die regte rigting was die promulgering van wet 76 van 1984 waarmee daar 'n onderskeid gemaak word tussen algemene en onderwysaangeleenthede en -belange. Die onderskeid tussen die "algemene" en die "eie" word egter in hierdie wet slegs gesien in terme van rasse- en etniese verskille. Die probleem wat in hierdie artikel behandel is, sal eers ten volle in die reine gebring kan word as die onderskeid tussen die "algemene" en die "eie" in terme van lewensbeskoulike (respektiewelik religieuse) verskille vertolk word. In religieus-"eie" skole sal Christene dan Christelike onderwys tot sy reg kan laat kom. 'n Aanduiding van wat in hierdie verband gedoen kan word, is die vordering wat die Christian Day School Movement en die Accelerated Christian Education in NoordAmerika gemaak het en nog steeds maak, sowel as die vordering wat deur Christian Education South Africa (C.E.S.A.) gemaak word. 


\section{BIRLIOGRAFIE}

BREGMAN, C. \& KOLE, I.A. samest. 1987. Visic op het onderwijs II: contouren van de Reformalorische school nader ingevuld Kampen : Kok.

EUDDING, DJ. 1987. Het wezen van reformatorisch onderwijs. (In Brcgman, C. \& Kole, I.A. samest. 1987. Visie op het onderwys II: contouren van de reformatorische school nader ingevuld. Kampen : Kok. p. 268-273.)

BRINK, B. du P. \& JONES, R.C. 1986. Naluur-en Skeikunde standerd 8. Kaapstad : Juta

DE GRAAF, A.H. \& OLTHUIS, J. 1973. Joy in Learning: An integrated curriculum for the elementary school. Volume I. Toronto: Curriculum Development Centre.

FOWLFR, S. 1987. Christian educational dislinctives. Potchefslroom : PU vir CHO.

FOWLER, S. 1989. Submission to the Committee of Revicw of New South Wales Schools. Presented on behalf of the Council of St. Paul's Grammar School Penrith Limited, Taylor Raod, Cranebrook. February 17.

LATEGAN, C.B. \& DE GROOT, H. 1983. Basiese bedryskennis st. 6 (alle kursusse). Johannesburg : Perskor.

SCHOEMAN, P.G. 1983. Wysgerige Pedagogick. Prctoria : SACUM

VAN DYKE, J 1988-9. Christian educalion. Christian educators joumal, 28(2):45. December 1988 . January 1989.

VISSER, G.H.J., NAGEL, I.P.C. \& BARNARD, C.J. 1981. Die wĉreld ons wereld. Die RSA. Aardrykskunde vir standerd 3. Johannesburg : Perskor. 
